\title{
Dioxirane oxidation of sulfur-containing organic compounds
}

\author{
Albert Lévai \\ Department of Organic Chemistry, University of Debrecen, Egyetem tér 1, \\ H-4010 Debrecen, Hungary \\ E-mail: alevai@tigris.klte.hu
}

\section{Dedicated to Professor Branko Stanovnik on the occasion of his $65^{\text {th }}$ birthday}

(received 06 May 03; accepted 30 June 03; published on the web 05 July 03)

\begin{abstract}
This short review describes the utilization of dioxiranes as convenient and extremely efficient electrophilic oxidants for the selective oxidation of sulfur-containing organic compounds. Relevant examples are included to illustrate the chemoselective and stereoselective oxidations of substances with several sites of oxidation. Electrophilic character of the dioxiranes is shown via the oxidation of compounds with two sulfur heteroatoms.
\end{abstract}

Keywords: Dioxiranes, electrophilic oxidants, chemoselective and stereoselective oxidation of sulfur atoms

\section{Contents}

Introduction

1. Preparation of isolated dioxiranes

2. Dioxirane oxidation of the sulfur atom of sulfur-containing organic compounds

2.1. Dioxirane oxidation of the thianthrene 5-oxide

2.2. Oxidation of thioethers and thiol esters

2.3. Chemoselective oxidation of the sulfur atom

2.4. Stereoselective sulfoxidation of sulfides with dimethyldioxirane

2.5. Oxidation of metal-coordinated thioethers with dimethyldioxirane

2.6. Miscellaneous oxidations

3. Closing remarks 


\section{Introduction}

During the last two decades, dioxiranes became prominent electrophilic oxidants utilized for a wide variety of oxidative transformations. These highly effective reagents have been successfully used, especially for the stereoselective epoxidation of alkenes. Another application is an oxygen insertion into a C-H bond of saturated hydrocarbons. Numerous aromatic hydrocarbons have also been reacted with dioxiranes to provide different oxidized products. As far as the dioxirane oxidation of heteroatoms is concerned, nitrogen, phosphorus, silicon and sulfur atoms should be emphasized. As a result of the intense research activity in this field, the utility of dioxiranes as versatile oxidizing agents has been discussed in several review articles. ${ }^{1-14}$ The reaction mechanism of dioxirane oxidations and the transition states involved have also been described in detail in these reviews and in other papers. ${ }^{15,16}$

Although in the above-mentioned review articles, the utility of dioxiranes is excellently illustrated by various examples, the oxidation of the sulfur atom usually receives less attention. For this reason, it appeared appropriate to compile the results of the dioxirane oxidation of the sulfur atom(s) of organic compounds in an individual review article. The aim of this short review is, therefore, to summarize the experimental experiences gained on the chemoselective and stereoselective oxidations of the sulfur atom of sulfur-containing compounds with other possible sites of oxidation.

\section{Preparation of isolated dioxiranes}

The first example regarding the formation of a dioxirane as an intermediate was in the oxidation of menthone by Caro's acid was published by Baeyer and Villiger as early as $1899 .{ }^{17}$ However, more than seven decades were required before the observation of the acceleration of the decomposition of the peroxymonosulfate ion $\left(\mathrm{HSO}_{5}{ }^{-}\right)$by ketones in the laboratory of Montgomery. ${ }^{18}$ Edwards et al. ${ }^{19}$ provided evidence for the formation of dioxirane intermediates in the ketone-catalyzed decomposition of the peroxymonosulfate ion. They also observed that the reaction rates depend on the ketone structure. Parent dioxirane was prepared by Suenram and $\operatorname{Lovas}^{20}$ by the reaction of ozone with ethylene at low temperature. Its structure was unequivocally elucidated by microwave measurements. Early synthetic applications of these oxidants were restricted to in situ generated dioxiranes.

A real milestone for the utilization of dioxiranes in synthetic organic chemistry was the preparation of isolated dimethyldioxirane (DMD) (1) in acetone solution by Murray and Jeyaraman in $1985 .^{21}$ This highly effective oxidant became extremely popular for a couple of 
years. For the synthesis of dimethyldioxirane a new simplified procedure has been worked out in the laboratory of $\mathrm{Adam}^{22}$ in 1991. This method provides 0.09-0.10 M acetone solution of dimethyldioxirane by using commercially available acetone, sodium hydrogen carbonate and potassium monoperoxysulfate (the triple salt $2 \mathrm{KHSO}_{5} \cdot \mathrm{KHSO}_{4} \cdot \mathrm{K}_{2} \mathrm{SO}_{4}$, trade names Curox, Caroat or Oxone) at a rigorously controlled temperature below $15^{\circ} \mathrm{C}$ and intensive stirring. After the invention of this procedure dimethyldioxirane became " the dioxirane" as one of the most widely used electrophilic oxidants in synthetic organic chemistry. In case a more concentrated and acetone-free dimethyldioxirane is needed, it can be prepared by the method worked out in the research group of Messeguer. ${ }^{23,24}$ They managed to prepare $0.4 \mathrm{M}$ dimethyldioxirane solution in $\mathrm{CH}_{2} \mathrm{Cl}_{2}$. Other chlorinated solvents like $\mathrm{CHCl}_{3}$ or $\mathrm{CCl}_{4}$ can also be used for this purpose. The dimethyldioxirane solution can be stored in the deep cooler of an ordinary refrigerator for weeks. However, it is advisable to determine the peroxide content of the solution before use.

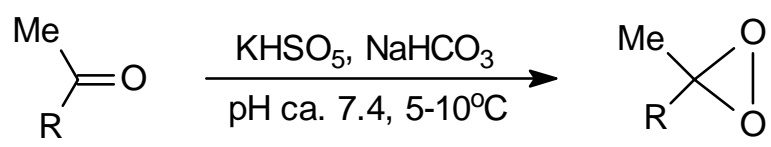

$$
\begin{aligned}
& \text { 1: } \mathrm{R}=\mathrm{Me} \\
& \text { 2: } \mathrm{R}=\mathrm{CF}_{3}
\end{aligned}
$$

\section{Scheme 1}

Another widely used dioxirane is methyl(trifluoromethyl)dioxirane (TFD) (2) first synthesized in the laboratory of Mello $^{25}$ by the oxidation of 1,1,1-trifluoropropanone with potassium monoperoxysulfate. Its concentration was ca. $0.8 \mathrm{M}$ in the parent 1,1,1trifluoropropanone. Ketone-free solutions of methyl(trifluoromethyl)dioxirane have also been prepared $^{26,27}$ by using chlorinated solvents as in the case of dimethyldioxirane. This helped its utilization as an oxidant and made available the study of the thermal and photochemical decomposition of this dioxirane. As far as the large scale application of methyl(trifluoromethyl)dioxirane is concerned, the high cost of the trifluoroacetone as starting material seems to be a serious restriction although this dioxirane is probably the most powerful nonmetallic peroxidic oxidant.

To close this chapter on the preparation of these two generally used isolated dioxiranes, it is worth mentioning that their decomposition is catalyzed by dialkyl ethers. ${ }^{28}$ For this reason, dialkyl ether impurities of the starting ketones and the solvents utilized for the oxidation reactions should be carefully controlled before use. 


\section{Dioxirane oxidation of the sulfur atom of sulfur-containing organic compounds}

\subsection{Dioxirane oxidation of thianthrene 5-oxide}

In the case of an oxidizing agent used for the oxidation of organic compounds it is necessary to know whether it is an electrophilic or a nucleophilic oxidant since this characteristic determines the utility of a reagent in a special case. This is true for dioxiranes, too. This problem started to be investigated even before the first preparation of the isolated dimethyldioxirane. ${ }^{21}$ The first difficulty encountered was to find the appropriate compound(s) to be oxidized by the actual oxidant. Adam et al. ${ }^{29}$ considered thianthrene 5-oxide (3) a convenient mechanistic probe for this purpose since this substance contains a nucleophilic sulfide and an electrophilic sulfoxide site for oxidation. On the basis of their first series of experiments both with in situ generated and isolated dimethyldioxirane (1) they concluded that the dimethyldioxirane (DMD) should act as a nucleophilic oxidant ${ }^{30}$ (Scheme 2$)$.

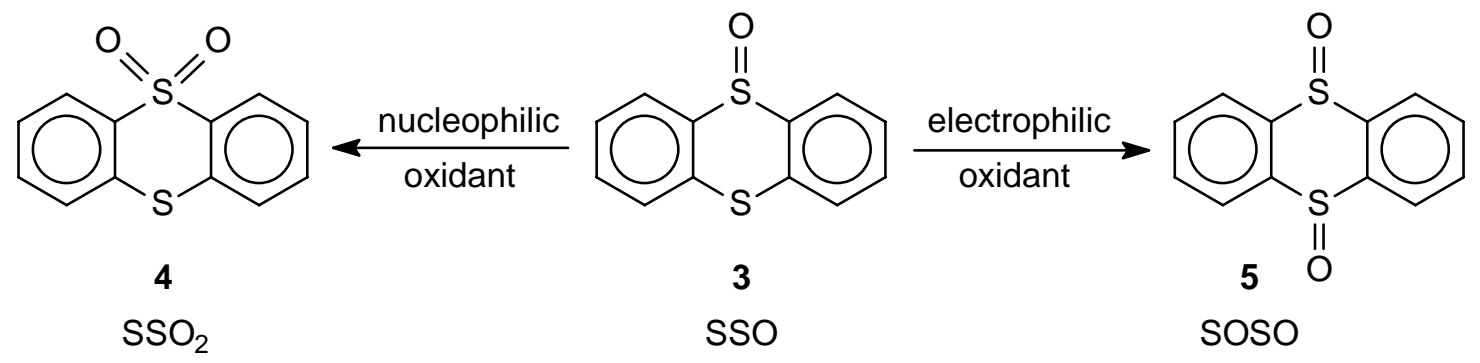

\section{Scheme 2}

The work of Clennan and $\mathrm{Yang}^{31}$ was an important contribution to determine whether dioxiranes are nucleophilic or electrophilic oxidants. They proved that the formation of sulfone 4 cannot take place via the DMD oxidation of the sulfinyl oxygen of thianthrene 5-oxide (3) (Scheme 3).

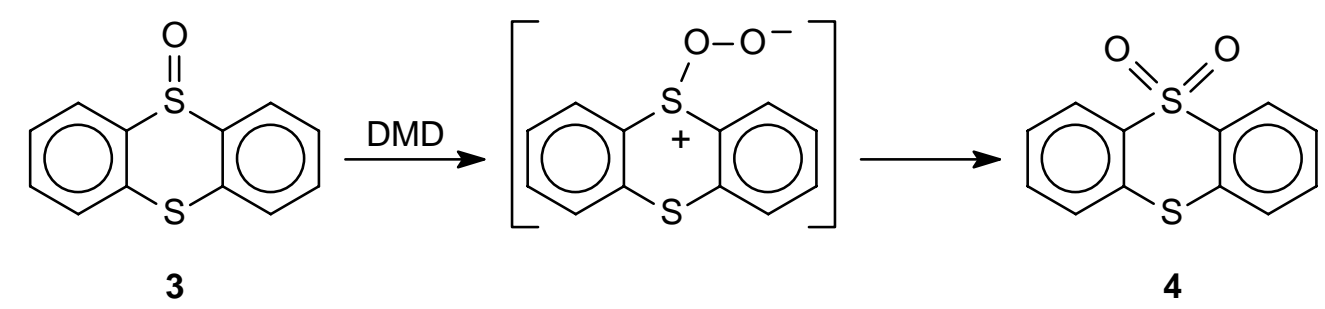

\section{Scheme 3}


Later, Adam et al. ${ }^{32-34}$ reinvestigated the dioxirane oxidation of the thianthrene 5-oxide (3). The careful analysis of all the reaction products unequivocally proved that both dimethyldioxirane (1) and methyl(trifluoromethyl)dioxirane (2) are strongly electrophilic oxidants. It meant that this sulfur-containing compound proved to be a really convenient mechanistic probe for this purpose.

\subsection{Oxidation of thioethers and thiol esters}

The oxidation of thioethers is among the most important chemical transformations of sulfurcontaining organic compounds. For this reason, it is not surprising that several procedures have been developed and various oxidizing agents have been utilized for this purpose. Synthesis of sulfoxides by the oxidation of thioethers has been extensively studied, which is illustrated by the fact that the results have been compiled and discussed in sevearal review articles. ${ }^{35-37}$

The relation between thioethers and dioxiranes is quite old. The peroxide content of the acetone solution of the isolated dimethyldioxirane was determined by the oxidation of methyl phenyl sulfide (thioanisole) to its sulfoxide which was quantified either by $\mathrm{GLC}^{38,39}$ or by ${ }^{1} \mathrm{H}$ NMR spectroscopy. ${ }^{40-42}$

In the early period of the utilization of dioxiranes, Colonna and Gaggero ${ }^{43}$ performed enantioselective sulfoxidation by in situ generated dioxiranes with the help of bovine serum albumin as chiral auxiliary. The enantiomeric excess ranged between $7 \%$ and $89 \%$ determined by NMR spectroscopy using Eu(tfc $)_{3}$ as chiral shift reagent or calculated on the basis of the published specific rotation of known optically active sulfoxides. Unfortunately, to our knowledge, no other enantioselective sulfoxidation with dioxiranes has hitherto been published.

Oxidation of simple sulfides with methyl(trifluoromethyl)dioxirane (2) has been investigated by Asensio et al. ${ }^{44}$ They found that the reaction of sulfides with TFD (2) provides preferentially sulfones even with the presence of competing sulfoxides. On this basis the involvement of a sulfurane intermediate in the oxidation was proposed by them.

Episulfones were first synthesized from episulfides with in situ generated methyl(trifluoromethyl)dioxirane (2) by Johnson and Taylor. ${ }^{45}$ Depending on the reaction conditions, episulfoxides have also been prepared with this oxidant.

Dimethyldioxirane oxidation of thiol esters (6) has also been published by Adam and Hadjiarapoglou. ${ }^{46}$ However, they managed to isolate only labile $\alpha$-oxo sulfones (7) (Scheme 4). Even with stoichiometric amounts of dioxirane it gave a 1:1 mixture of $\alpha$-oxo sulfone (7) and the unreacted starting material. No $\alpha$-oxo sulfoxide was detected by ${ }^{1} \mathrm{H}-\mathrm{NMR}$ spectroscopy. They supposed that the initially formed $\alpha$-oxo sulfoxides undergo a disproportionation in the starting thiol esters (6) and $\alpha$-oxo sulfones (7). 


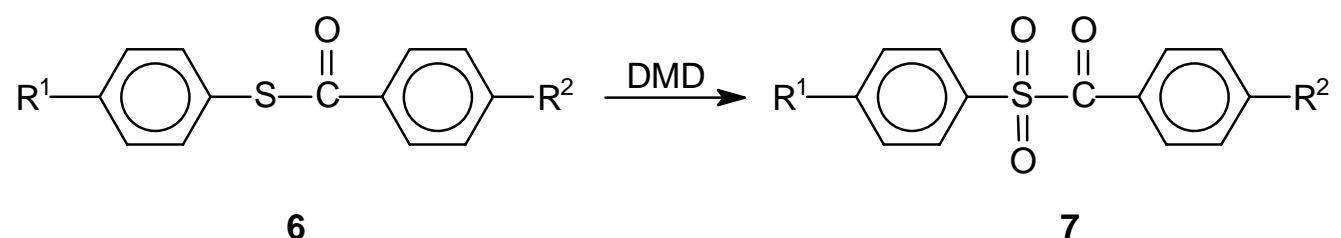

\section{Scheme 4}

The mechanism of dioxirane oxidation of sulfides and sulfoxides has been studied by McDuell with the help of $a b$ initio calculations. ${ }^{47}$ It was found that in acetone as a typical solvent the conversion of sulfide into sulfoxide is stabilized, whereas the oxidation of the sulfoxide into sulfone is destabilized. This is in agreement with the electrophilic character of these oxidizing agents.

Recently, Asensio et al. ${ }^{48}$ have investigated the mechanism of the dioxirane oxidation of sulfides in their general and systematic studies. They established that sulfones are the main oxidation products with methyl(trifluoromethyl)dioxirane (2) under different reaction conditions. The mechanism involves an initial electrophilic attack of the dioxirane to the sulfur atom which is followed by several steps leading to the formation of sulfone. They have also concluded that the oxidation of sulfides first to sulfoxides and then to sulfones is valid only in particular cases. On all these bases, it appears to the reviewer that the study of the mechanism of the dioxirane oxidation of the sulfur atom will be continued in the future, too.

\subsection{Chemoselective oxidation of the sulfur atom}

In many organic compounds there are several sites of oxidation, e.g. sulfur atom or olefinic double bond(s). In such cases it is necessary to find the appropriate oxidant to oxidize either the sulfur atom or the double bond(s) chemoselectively. Recently, we have accomplished a systematic oxidation study of exocyclic $\alpha, \beta$-unsaturated ketones, víz. 2-arylidene-1-indanones, 1-tetralones, -1-benzosuberones, aurones, 3-arylidenechromanones and -flavanones. It has been found that dioxiranes $\mathbf{1}$ and $\mathbf{2}$ are the oxidants of choice for the diastereoselective epoxidation of these $\alpha, \beta$-enones. ${ }^{49-54}$ As part of this systematic study, the dioxirane oxidation of the related sulfur-containing compounds 8, víz. 1-thioaurones, 3-arylidene-1-thiochromanones and -1thioflavanones has also been investigated. ${ }^{55}$ In one case these compounds were allowed to react with isolated DMD (1), depending on the amount the oxidant, sulfoxides 9 and/or sulfones 10 were obtained (Scheme 5). In another case the much more powerful TFD (2) was used, only epoxides 11 of 3-arylidene-1-thiochromanone 1,1-dioxides 10 could be prepared. In similar reaction mixtures of 1-thioaurones and 3-arylidene-1-thioflavanones no epoxide could be 
detected even if a large excess of TFD (2) was used. In conclusion, in the case of sulfur containing $\alpha, \beta$-enones 8 dimethyldioxirane proved to be a reagent of choice for the completely chemoselective oxidation of their sulfur atom to afford sulfoxides $\mathbf{9}$ or sulfones $\mathbf{1 0}$ depending on the amount of the oxidant. The epoxidation of their strongly electron deficient double bond took place only in the case of 3-arylidene-1-thiochromanones with TFD (2).

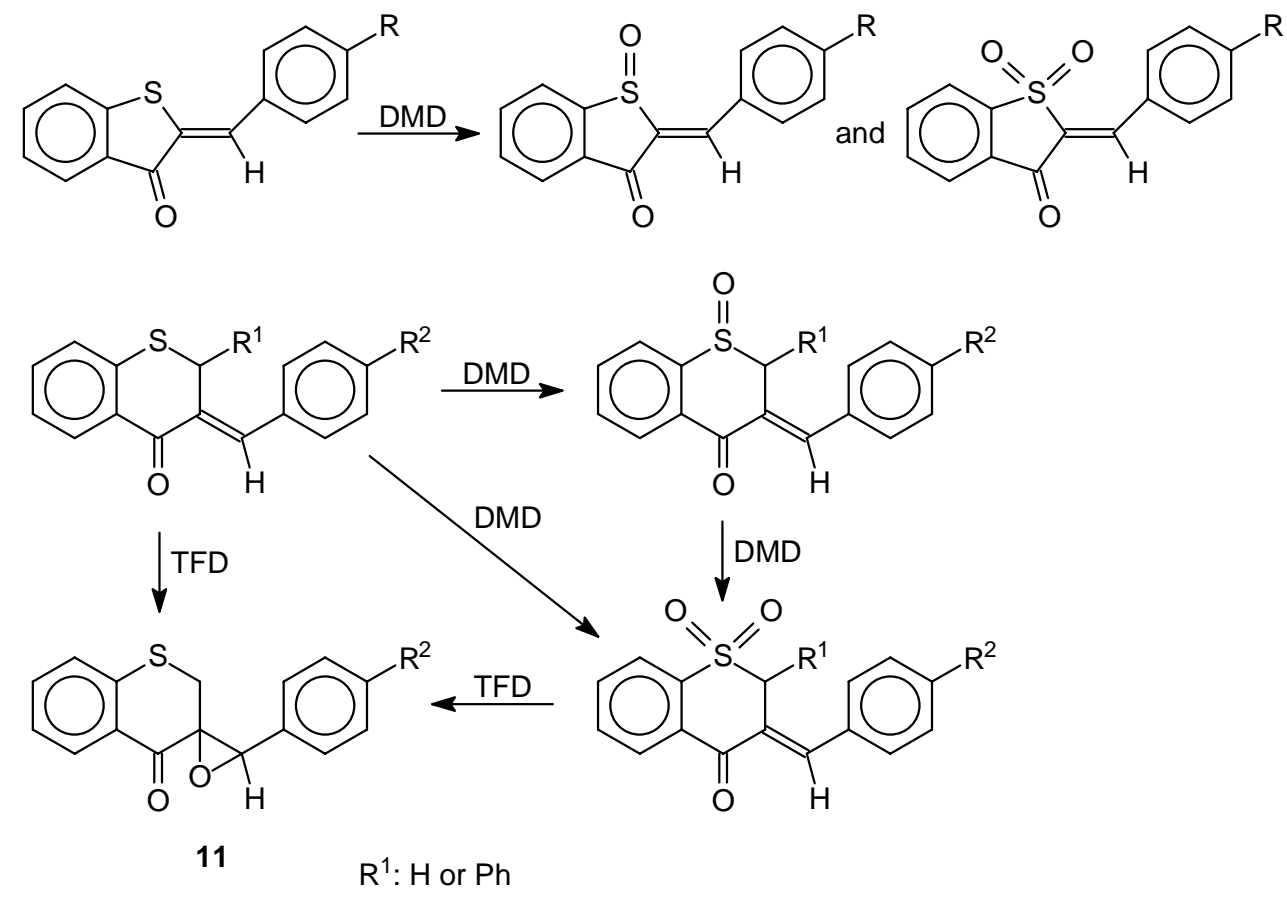

8: sulfide, 9: sulfoxide, 10: sulfone

\section{Scheme 5}

Another group of sulfur-containing organic compounds with olefinic double bonds is vinyl sulfides. Their oxidation with isolated dimethyldioxirane (1) also proved to involve a completely chemoselective oxidation of the sulfur atom. Depending on the amount of the DMD (1) their sulfoxides or sulfones can be prepared in good yields. ${ }^{55-57}$ We have performed the dimethyldioxirane (1) oxidation of 1-thiochromones 12 which also belong to a group of sulfurcontaining compounds with an olefinic double bond ${ }^{58}$ (Scheme 6). Again, a completely chemoselective oxidation of the sulfur atom was observed yielding sulfoxides $\mathbf{1 3}$ or sulfones 14 depending on the amount of the DMD (1) used. 


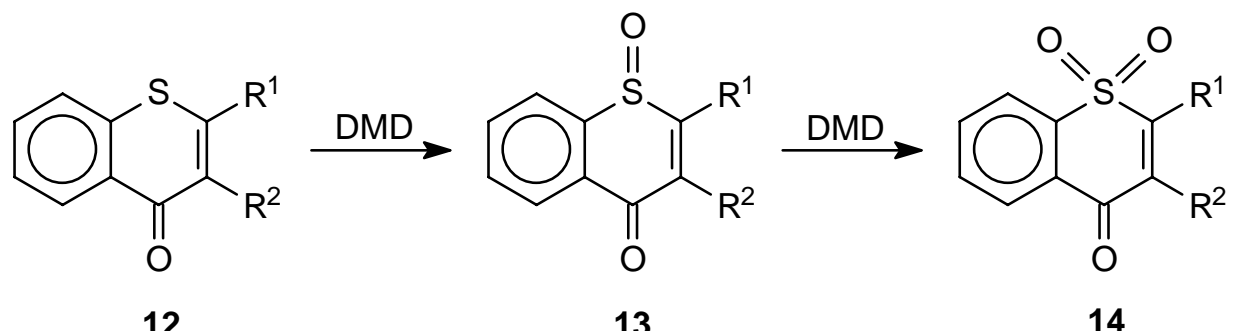

\section{Scheme 6}

As mentioned above, not only the sulfur but also the nitrogen heteroatom can be oxidized with dioxiranes. For this reason, to study the chemoselective utilization of these versatile oxidants, those examples seem to be especially important where sulfur and nitrogen atoms and olefinic double bond(s) are present in a molecule. Cephalosporins or 2,3-dihydro-benzothiazoles belong to these types of compounds. Their sulfur atoms were chemoselectively oxidized with isolated dimethyldioxirane (1). ${ }^{59,60}$ Neither the double bond nor the nitrogen atom was oxidized even with a large excess of the oxidant.

\subsection{Stereoselective sulfoxidation of sulfides with dimethyldioxirane}

Dioxiranes are versatile reagents for the oxidation of thioethers. As far as cyclic thioethers are concerned, if a group of high spatial demand is connected to the adjacent carbon atom, diastereomeric sulfoxides are expected. Therefore, it is beneficial to find a bulky electrophilic oxidant the attack of which may take place at the strerically less hindered side. Owing to their spatial demand, the DMD (1) and the TFD (2) can fulfil this requirement. Hereafter some examples will be shown for such a utilization of the isolated dimethyldioxirane (1).

Diastereomerically pure penicillin sulfoxides were prepared by isolated DMD (1) in the laboratory of Mascaretti. ${ }^{61}$ In this case the excellent selectivity, high yield and mild reaction conditions should be emphasized.

Because of their wide range of bioactivities, 1,5-benzothiazepines became especially important compounds in drug research. ${ }^{62,63}$ One of their subclasses contains the 2,3-dihydro-1,5benzothiazepin-4(5H)-ones among which there are compounds with antidepressant and antianginal activities. For this reason, their chemical tansformations including the oxidation of the sulfur atom have been extensively studied. Several procedures were used for their sulfoxidation ${ }^{64-70}$ but diastereomeric mixtures of sulfoxides were obtained in most cases. The isolated DMD (1) proved to be the oxidant of choice for diastereoselective sulfoxidation of 2,3dihydro-1,5-benzothiazepin-4(5H)-ones substituted at the C-2 atom 15 providing transsulfoxides 16 as single isolable product in most cases ${ }^{71}$ (Scheme 7). 
<smiles>[R]C1CC(=O)Nc2ccccc2S1</smiles>

15

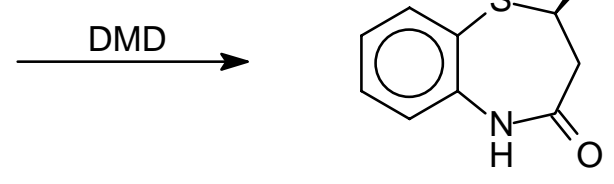

16

$\mathrm{R}: \mathrm{Me}, \mathrm{Ph}, 2$-furyl

\section{Scheme 7}

Sulfoxidation of 1-thiochromanones $\mathbf{1 7}$ substituted at position 2 is also a highly diastereoselective reaction with isolated DMD (1) providing cis-sulfoxides 18 as major product ${ }^{28}$ (Scheme 8 ). The stereochemistry of sulfoxides 18 have been elucidated by NMR spectrsocopy and by X-ray diffraction. ${ }^{72}$<smiles>[R]C1CC(=O)c2ccccc2S1</smiles>

17

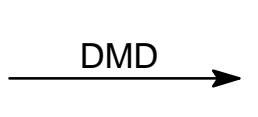

$\mathrm{R}: \mathrm{Me}, \mathrm{Ph}$

\section{Scheme 8}

As discussed in section 2.3, 3-arylidene-1-thioflavanones were oxidized either with DMD (1) or with TFD (2) $)^{55}$ only the sulfur atom was oxidized. The same was observed with $m$ chloroperbenzoic acid as another electrophilic oxidant. ${ }^{73}$ Therefore, we have epoxidized 3arylidene-1-thioflavanones 8 with nucleophilic oxidants, víz. alkaline hydrogen peroxide and $\mathrm{NaOCl}$ and diastereomeric mixtures of trans,cis- and trans,trans-epoxides 19 were obtained. The diastereomers were separated by column chromatography to afford stereohomogeneous epoxides trans,cis-19 and trans,trans-19 (Scheme 9). ${ }^{74,75}$ 

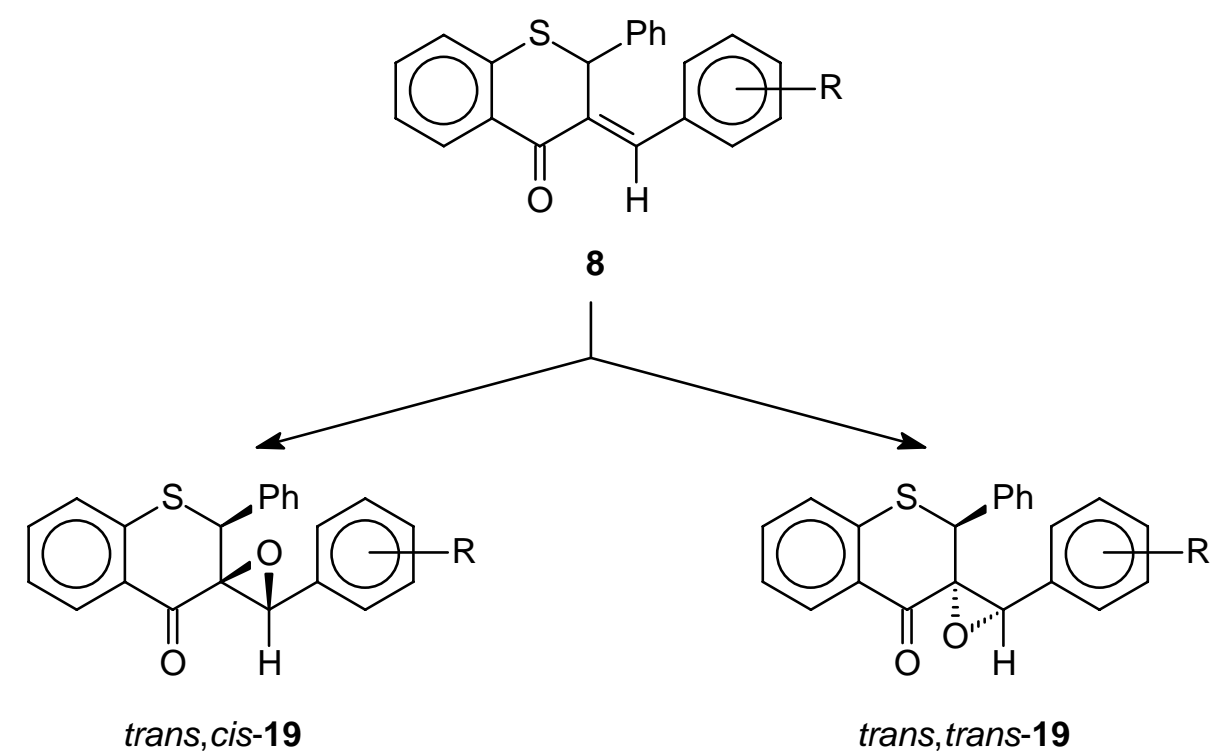

\section{Scheme 9}

Epoxides trans,cis-19 and trans,trans-19 were allowed to react with isolated dimethyldioxirane (1) and sulfoxides trans,cis-20 and trans,trans-20 were obtained in complete diastereoselectivity. ${ }^{76}$ Relative configuration of the sulfoxide oxygen atom and the adjacent phenyl group has been determined by NMR spectroscopy and by $a b$ initio calculations ${ }^{77}$ (Scheme 10). Sulfoxides 20 were oxidized by isolated DMD (1) to obtain sulfones trans,cis-21 and trans,trans-21. It can be concluded that we managed to synthesize all the possible oxidized products of 3-arylidene-1-thioflavanones either by isolated DMD (1) as electrophilic oxidant ${ }^{55,76}$ or by nucleophilic oxidants. ${ }^{74}$ 


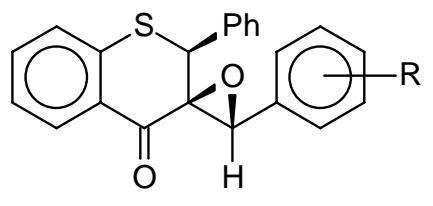

trans,cis-19<smiles>[R]c1ccc(C2OC23C(=O)c2ccccc2[S](O)C3[Y9](C)(C)C)cc1</smiles>

trans, cis-20<smiles>[R]c1ccc(C2OC23C(=O)c2ccccc2S(=O)(=O)C3O[Y6](C)(C)C)cc1</smiles>

trans,cis-21<smiles>[R]c1ccc(C(O)C2([2H])C(=O)c3ccccc3SC2c2ccccc2)cc1</smiles>

trans,trans-19

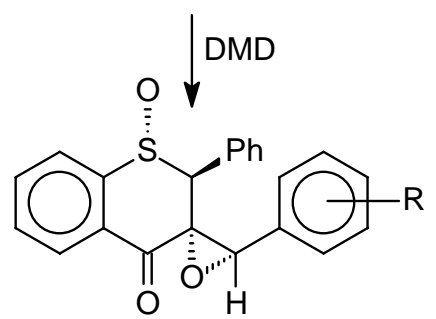

trans,trans-20<smiles>[R]c1ccc([C@H](O)[C@]2(O)C(=O)c3ccccc3S(=O)(=O)[C@@H]2c2ccccc2)cc1</smiles>

trans, trans-21

\section{Scheme 10}

\subsection{Oxidation of metal-coordinated thioethers with dimethyldioxirane}

In the previous paragraphs of this review article, the isolated dimethyldioxirane (1) is described as a convenient reagent for the oxidation of thioethers to obtain sulfoxides or sulfones depending on the amount of the oxidant. Since dioxiranes are electrophilic oxidants, a susbtance with considerable nucleophilic character can be beneficially oxidized with these oxidizing agents. Due to orbital interaction, transition metal thiolates $\mathrm{L}_{\mathrm{x}} \mathrm{M}-\mathrm{S}-\mathrm{Q}$ are usually far better nucleophiles than thioethers R-S-Q. Adam et al. oxidized ruthenium thiolates 22 with isolated DMD (1) to obtain sulfinato complexes 23 in excellent yield (Scheme 11). ${ }^{78}$ They managed to synthesize chiral sulfoxides by DMD (1) oxidation of ruthenium coordinated thioethers. ${ }^{79}$ Tungsten-coordinated thioethers were also oxidized with isolated dimethyldioxirane (1) to yield sulfoxides or sulfones depending on the amount of oxidant used. ${ }^{78}$ 


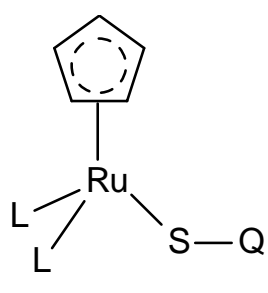

22

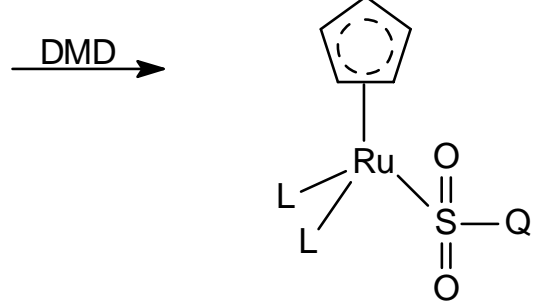

23

\section{Scheme 11}

Cyclic sulfoxides 25 were prepared by Gree et al. ${ }^{80}$ by the oxidation of the corresponding iron-coordinated cyclic sulfides with Oxone (Scheme 12).

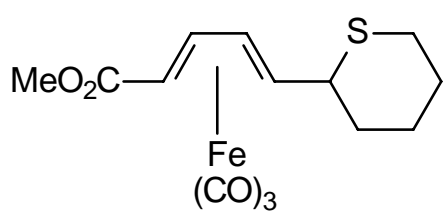

24

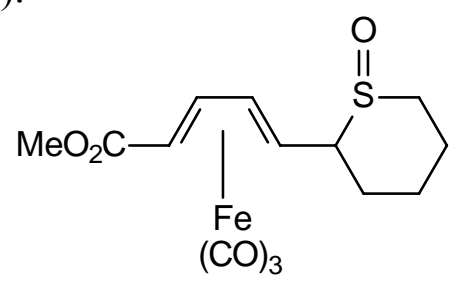

25

\section{Scheme 12}

All these examples prove that in some cases it is beneficial to use metal-coordinated thioethers as substrates for the dioxirane oxidation of their sulfur atom.

\subsection{Miscellaneous oxidations}

In the previous sections the dioxirane oxidation of the sulfur atom of thioethers is described. However, in the sulfur-containing organic compounds, sulfur atom may participate in the formation of other functional groups too. Such a functional group is e.g. in the thioaldehydes. Oxidation of thioaldehydes 26 with isolated DMD (1) provided a 20:1 mixture of sulfine isomers (E)-27 and (Z)-27 at ambient temperature. However, at $-78{ }^{\circ} \mathrm{C}$ only (E)-27 was formed (Scheme 13). ${ }^{81}$

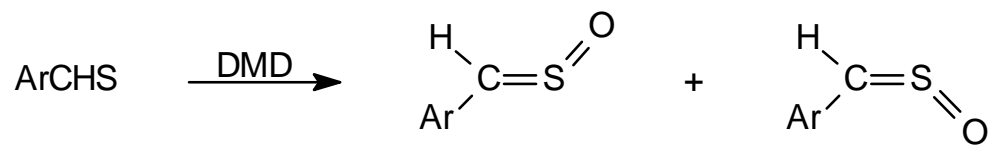




\section{Scheme 13}

Since the trisulfane linkage is present in antitumor antibiotics, ${ }^{82-85}$ the interest in this linkage has increased and its oxidation has also been studied. Clennan and Stensaas ${ }^{86}$ investigated the oxidation of bis(p-methoxyphenyl)trisulfane and its oxides with DMD (1) and with TFD (2). In case the oxidation was performed at subambient temperature, various oxidized products were detected by low-temperature NMR measurements. However, these materials proved to be unstable at room temperature. Nevertheless, dioxiranes can be utilized for the oxidation of these sulfur-containing compounds as well.

Curci et al. ${ }^{87}$ managed to oxidize sulfilimines 28 with DMD (1) to afford their sulfoximines 29 (Scheme 14). They succeeded in using this procedure for the preparation of optically active sulfoximines, e.g. $S$-(p-tolyl)-S-methyl- $N$-(p-tolylsulfonyl)sulfilimine was oxidized to the appropriate sulfoximine without loss of optical purity.

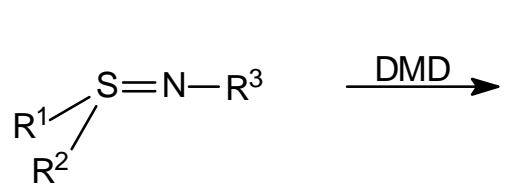

28<smiles>[R]N=S([R])([R])=O</smiles>

29

\section{Scheme 14}

As a last example, the DMD (1) oxidation of tetrathiolanes is mentioned. Dimethyldioxirane (1) oxidation of di-1-adamantyltetrathiolane provided di-1-adamantyl-thiirane 1-oxide. ${ }^{88}$

\section{Closing remarks}

Results compiled and discussed in this short review unequivocally prove that dioxiranes have became versatile and important oxidants in the field of sulfur-containing organic compounds. Especially their utility in chemoselective oxidation of the sulfur atom and the stereoselective sulfoxidation of sulfides should be emphasized. In the future, enantioselective sulfoxidation with in situ generated optically active dioxiranes seems to be an advantageous use of these oxidants in this field.

Literature data published until April 2003 have been included as references to help the reader to find original articles for the preparation of a particular compound or to select an experimental method to solve a synthetic task. 


\section{Acknowledgements}

The preparation of the present review article was sponsored by the Hungarian National Research Foundation (Grant No. OTKA T034123) for which our gratitude is expressed.

\section{References}

1. Adam, W.; Curci, R.; Edwards, J. O. Acc. Chem. Res. 1989, 22, 205.

2. Murray, R. W. Chem. Rev. 1989, 89, 1187.

3. Curci, R. In Advances in Oxygenated Processes; Baumstark, A. L., Ed.; JAI Press: Greenwich, 1990; Vol. 2, pp 1-59.

4. Adam, W.; Hadjiarapoglou, L.; Curci, R.; Mello, R. Organic Peroxides; Ando, W., Ed.; Wiley: New York, 1992; pp 195-219.

5. Adam, W.; Hadjiarapoglou, L. Top. Curr. Chem. 1993, 164, 45.

6. Clennan, E. L. Trends Org. Chem. 1995, 5, 231.

7. Curci, R.; Dinoi, A.; Rubino, M. F. Pure Appl. Chem. 1995, 67, 811.

8. Adam, W.; Smerz, A. K. Bull. Soc. Chim. Belg. 1996, 105, 581.

9. Adam, W.; Smerz, A. K.; Zhao, C. G. J. prakt. Chem. 1997, 339, 298.

10. Denmark, S. E.; Wu, Z. Synlett 1999, 847.

11. Kazakov, V. P.; Voloshin, A. I.; Kazakov, D. V. Russ. Chem. Rev. 1999, 68, 253.

12. Adam, W.; Mitchell, C. M.; Saha-Möller, C. R.; Weichold, O. Structure and Bonding; Meunier, B., Ed.; Springer Verlag: Berlin, 2000, Vol. 97, pp 237-285.

13. Adam, W.; Saha-Möller, C. R.; Ganeshpure, P. A. Chem. Rev. 2001, 101, 3499.

14. Adam, A.; Saha-Möller, C R.; Zhao, C. G. Org. React.; Overman, L. E., Ed.; Wiley: New York, 2002, Vol 61, pp 219-516.

15. Bach, R. D.; Glukhovtsev, M. N.; Canepa, C. J. Am. Chem. Soc. 1998, 120, 775.

16. Deaubel, D. V. J. Org. Chem. 2001, 66, 3790.

17. Baeyer, A.; Villiger, V. Chem. Ber. 1899, 32, 3625.

18. Montgomery, R. E. J. Am. Chem. Soc. 1974, 96, 7820.

19. Edwards, J. O.; Pater, R. H.; Curci, R.; Di Furia, F. Photochem. Photobiol. 1979, 30, 63.

20. Suenram, R. D.; Lovas, F. J. J. Am. Chem. Soc. 1978, 100, 5117.

21. Murray, R. W.; Jeyaraman, R. J. Org. Chem. 1985, 50, 2847.

22. Adam, W.; Bialas, J.; Hadjiarapoglou, L. Chem. Ber. 1991, 124, 2377.

23. Ferrer, M.; Gibert, M.; Sánchez-Baeza, F.; Messeguer, A. Tetrahedron Lett. 1996, 37, 3585. 
24. Gibert, M.; Ferrer, M.; Sánchez-Baeza, F.; Messeguer, A. Tetrahedron 1997, 53, 8643.

25. Mello, R.; Fiorentino, M.; Sciacovelli, O.; Curci, R. J. Org. Chem. 1988, 53, 3890.

26. Adam, W.; Curci, R.; González-Nunez, M. E.; Mello, R. J. Am. Chem. Soc. 1991, 113, 7654.

27. Adam, W.; Asensio, G.; Curci, R.; González-Nunez, M. E.; Mello, R. J. Am. Chem. Soc. 1992, 114, 8345.

28. Ferrer, M.; Sánchez-Baeza, F.; Casas, J.; Messeguer, A. Tetrahedron Lett. 1994, 35, 2981.

29. Adam, W.; Haas, W.; Seiker, G. J. Am. Chem. Soc. 1984, 106, 5020.

30. Adam, W.; Chan, Y. Y.; Cremer, D.; Gauss, J.; Scheutzow, D.; Schindler, M. J. Org. Chem. 1987, 52, 2800.

31. Clennan, E. L.; Yang, K. J. Org. Chem. 1993, 58, 4504.

32. Adam, W.; Golsch, D. Chem. Ber. 1994, 127, 1111.

33. Adam, W.; Golsch, D.; Görth, F. C. Eur. Chem. J. 1996, 255.

34. Adam, W.; Golsch, D. J. Org. Chem. 1997, 62, 115.

35. Madesclaire, M. Tetrahedron 1986, 42, 5459.

36. Drabinowicz, J.; Kielbasinski, P.; Mokilajczyk, M. In The Chemistry of Sulfones, Sulfoxides and Cyclic Sulfides; Patai, S.; Rappoport, Z., Eds.; Wiley: Chichester, 1994, pp 109-308.

37. Mata, E. G. Phosporus, Sulfur, and Silicon 1996, 117, 231.

38. Murray, R. W.; Jeyaraman, R.; Krishna Pillay, M. J. Org. Chem. 1987, 52, 746.

39. Murray, R. W.; Shiang, D. L. J. Chem. Soc., Perkin Trans. 2 1990, 349.

40. Adam, W.; Hadjiarapoglou, L. Chem. Ber. 1990, 123, 2077.

41. Adam, W.; Hadjiarapoglou, L.; Smerz, A. Chem. Ber. 1991, 124, 227.

42. Adam, W.; Hadjiarapoglou, L.; Jager, V.; Klicic, J.; Seidel, B.; Wang, X. Chem. Ber. 1991, $124,2361$.

43. Colonna, S.; Gaggero, N. Tetrahedron Lett. 1989, 30, 6233.

44. Asensio, G.; Mello, R.; González-Nunez, M. E. Tetrahedron Lett. 1996, 37, 2299.

45. Johnson, P.; Taylor, R. J. K. Tetrahedron Lett. 1997, 38, 5873.

46. Adam, W.; Hadjiarapoglou, L. Tetrahedron Lett. 1992, 33, 469.

47. McDouell, J. J. W. J. Org. Chem. 1992, 57, 2861.

48. González-Nunez, M. E.; Mello, R.; Royo, J.; Rios, J. V.; Asensio, G. J. Am. Chem. Soc. 2002, 124, 9154.

49. Adam, W.; Hadjiarapoglou, L.; Lévai, A. Synthesis 1992, 436.

50. Adam, W.; Halász, J.; Lévai, A.; Nemes, C.; Patonay, T.; Tóth, G. Liebigs Ann. Chem. 1994, 795.

51. Nemes, C.; Lévai, A.; Patonay, T.; Tóth, G.; Boros, S.; Halász, J.; Adam, W.; Golsch, D. J. Org. Chem. 1994, 59, 900. 
52. Adam, W.; Halász, J.; Jámbor, Z.; Lévai, A.; Nemes, C.; Patonay, T.; Tóth, G. J. Chem. Soc., Perkin Trans. 1 1996, 395.

53. Adam, W.; Halász, J.; Jámbor, Z.; Lévai, A.; Nemes, C.; Patonay, T.; Tóth, G. Monatsh. Chem. 1996, 127, 683.

54. Adam, W.; Lévai, A.; Mérour, I. Y.; Nemes, C. , Patonay, T. Synthesis 1997, 268.

55. Adam, W.; Golsch, D.; Hadjiarapoglou, L.; Lévai, A.; Nemes, C.; Patonay, T. Tetrahedron 1994, 50, 13113.

56. Lautens, M.; Fillion, E.; Sampat, M. Tetrahedron Lett. 1998, 39, 1501.

57. Lévai, A.; Hevesi, L. Unpublished results.

58. Patonay, T.; Adam, W.; Lévai, A.; Kövér, P.; Németh, M.; Peters, E.M.; Peters, K. J. Org. Chem. 2001, 66, 2275.

59. Gunda, E. T.; Tamás, L.; Sályi, S.; Nemes, C.; Sztaricskai, F. Tetrahedron Lett. 1995, 36, 7111.

60. Lévai, A.; Jekő, J. Arkivoc 2003, (v), 19.

61. Danelon, G. D.; Mata, E. G.; Mascaretti, O. A. Tetrahedron Lett. 1993, 34, 7877.

62. Lévai, A. Pharmazie 1999, 54, 719.

63. Lévai, A. J. Heterocycl. Chem. 2000, 37, 199.

64. DeVita. R. J.; Schoen, V. R.; Doldouras, G. A.; Fisher, M. H.; Wyvratt, M. J.; Cheng, K. ; Chan, W. W. S.; Butler, B. S.; Smith, R. G. Bioorg. Med. Chem. Lett. 1995, 5, 1281.

65. Campriani, G.; Nacci, V.; Fiorini, I.; DeFilippis, M. P.; Garofalo, A,; Greco, G.; Novellino, E.; Altamura, S.; DiRenzo, L. J. Med. Chem. 1996, 39, 2672.

66. Slade, J.; Stanton, J. L.; Ben-David, D.; Mazzenga, G. C. J. Med. Chem. 1985, $28,1517$.

67. Miyazaki, M.; Iwakuma, T.; Tanaka, T. Chem. Pharm. Bull. 1978, 26, 2889.

68. Puzicha, G.; Lévai, A.; Snatzke, G. Monatsh. Chem. 1990, 121, 293.

69. Lévai, A. Acta Chim. Acad. Sci. Hung. 1979, 102, 141.

70. Breitschuh, R.; Seebach, D. Synthesis 1992, 1170.

71. Patonay, T.; Adam, W.; Jekő, J., Kövér, K. E.; Lévai, A.; Németh, M.; Peters, K. Heterocycles 1999, 51, 85.

72. Peters, K.; Peters, E. M.; Adam, W.; Kövér, P. ; Lévai, A.; Patonay, T. Z. Kristallogr. 2000, 215, $217,219$.

73. Bierne, J. J.; O’Sullivan, W. I. Proc. Roy. Irish Acad. 1977, 77B, 331.

74. Lévai, A.; Tóth, G.; Kovács, J.; Patonay, T.; Vass, E. B. Monatsh. Chem. 2001, $132,707$.

75. Tóth, G.; Kovács, J.; Lévai, A.; Kleinpeter, E.; Koch, A. Magn. Reson. Chem. 2001, 39, 251.

76. Lévai, A; Patonay, T.; Tóth, G.; Kovács, J.; Jekő, J. J. Heterocycl. Chem. 2002, 39, 817.

77. Kovács, J; Tóth, G.; Simon, A.; Lévai, A.; Koch, A.; Kleinpeter, E. Magn. Reson. Chem. 2003, 41, 193. 
78. Schenk, W.A.; Frisch, J.; Adam, W.; Prechtl, F. Inorg. Chem. 1992, 31, 3329.

79. Schenk, W.A.; Frisch, J.; Adam, W.; Prechtl, F. Angew. Chem. Int. Ed. Engl. 1994, 33, 1609.

80. Hachem, A.; Toupet, L.; Grée, R. Tetrahedron Lett. 1995, 36, 1849.

81. Watanabe, S.; Yamamoto, T.; Kawashima, T.; Inamoto, N.; Okazaki, R. Bull. Chem. Soc. Jpn. 1996, 69, 719.

82. Lee, M. D.; Dunne, T. S.; Siegel, M. M.; Chang, C. C.; Morton, G. O.; Borders, D. B. J. Am. Chem. Soc. 1987, 109, 3464.

83. Lee, M. D.; Dunne, T. S.; Chang, C. C.; Ellestad, G. A.; Siegel, M. M.; Morton, G. O. J. Am. Chem. Soc. 1987, 109, 3466.

84. Golik, J.; Clardy, J.; Dubay, G.; Groenewold, G.; Kawaguchi, H.; Konishi, M.; Krishnan, B.; Ohkuma, H.; Saitoh, K.; Doyle, T. W. J. Am. Chem. Soc. 1987, 109, 3461.

85. Golik, J.; Dubay, G.; Groenewold, G.; Kawaguchi, H.; Konishi, M.; Krsihnan, B.; Ohkuma, H.; Saitoh, K.; Doyle, T. W. J. Am. Chem. Soc. 1987, 109, 3462.

86. Clennan, E. L.; Stensaas, K. L. J. Org. Chem. 1996, 61, 7911.

87. Gaggero, N.; D’Accolti, L.; Colonna, S.; Curci, R. Tetrahedron Lett. 1997, 38, 5559.

88. Jin, Y. N.; Ishii, A.; Sugihara, Y.; Nakayama, J. Tetrahedron Lett. 1998, 39, 3525. 